\title{
Comparison between Chinese and American Health Management Talent Training Modes
}

\author{
LiangYu Jiao, He Wang \\ School of Gannan Medical University, Jiangxi Ganzhou 341000, China \\ 1882286@qq.com
}

\begin{abstract}
Key words: health management; talent training; China; America
\end{abstract}
\begin{abstract}
Traditional administrative management system and degree training regulation have a great influence on the training of Chinese health management talents, resulting in the shortage of professional talents of health management in the healthcare industry. Such phenomenon remains nowadays. Meanwhile, with the increasing of people's living standard and the development of medical level, people propose more demand for health. Traditional talent training mode fails to keep pace with the development of healthcare industry at the new time. Thus, I made research on the training system of American health management talents and compared with the problems existed in the current Chinese health management talent training mode. I proposed some suggestions on the professional core courses and basic courses reformation.
\end{abstract}

Chinese health management education began relatively late. Through long-term development, it has formed corresponding discipline system and professional field, a comprehensive education system from university to doctoral stage. The courses include Medical Science, Management Science and Health Science etc. But, due to the influence of the planned economic system and traditional health administrative management system at the early stage, Chinese health management talent training still can not satisfy the demand of healthcare industry in the positioning of training objects and training mode. With the reformation of management education and healthcare system with the addition of the social fervor of MBA and MPA, MBA and MPA talents became the popular talents in the healthcare industry, triggering the reformation of course setting, or the additional bachelor, master and doctor education of Health Management on the basis of Management College. As most of the original medical colleges had been merged into comprehensive universities, the original majors of Public Health and Health Management began to draw close to the management direction. Such phenomenon all reflected the urge demand of senior management talents of Chinese healthcare system and the new requirements in the health management talent training. The following will propose some related suggestions by reference to American health management talent training mode combined with the current Chinese training mode.

\section{American Health Management Talent Training}

America attaches great importance to the training of health management talents. There has been a whole set of relatively complete training system. Early in the 1930s, people realized the specialty of healthcare industry relative to other industries. People must receive certain professional training to engage in the industry, resulting in MHA training plan. University of Chicago established MHA course at the earliest time in 1934. Then over 60 universities all set this course. It gradually developed to be the most famous health management talent training plan in America. MHA is the generic term for American health management degree and has been extensively applied in America with strong universality. MHA sets related courses and training plan based on the work and responsibility of senior management talents in the healthcare industry. In recent years, American MHA training plan is relatively close to Business Management. Its training plan, study content, teachers and equipment are all closely related to medical industry health management. 


\section{Training goals}

The medical colleges or public health colleges in universities in each American state are the health management education bases for the state. According to incomplete statistics, over 30 universities set health management courses at the bachelor stage; over 60 universities set health management education courses at the master stage; over 20 universities set management courses at the doctor stage; 19 universities even set management-direction further education. As different education levels, the training goals of health management talents are also different. The education at the bachelor stage mainly trains general and medium level management talents for medical institutions; the education at the master stage mainly trains medium and senior management talents for medical institutions, government health departments and social welfare departments and so on; the education at the doctor stage mainly trains research personnel for government departments, professional research institutions and universities, and also trains a few top management talents for medical health institutions. In the global scope, American health management talent training is relatively mature and its training levels also include all the higher education stages. But it mainly targets at the training at the master stage. Students applying for master degree are generally required to have related work experiences or bachelor degree.

\section{Teaching contents and courses setting}

Through the investigation and analysis on the teaching contents of Health Education Management of the top ten universities, I discovered that courses required for this major mainly include 10 categories of Management Science, Economics Science, Laws, Tool Discipline, Health System, Internal and External Strategies for Medical Institutions, Summary Course, Practical and Research Course (1). In consideration of such courses setting, it can be clearly discovered that the major of Health Management in American universities have been very mature. Through the research on the course planning of the Health Management in America, it discovered a common problem. All universities did not include Health Management Education Course into the medical courses, but rather included the natural and cultural social discipline knowledge into the courses of Health Management. Due to relatively strong autonomy, American universities can decide the training goals and requirements for Health Management on their own. So the syllabus shows a diversified state. The courses settings of each college are different. The above mentioned that education levels of Health Management in America included from the bachelor stage to doctor stage, so there was also great difference in courses setting. For example, the health management education in Business College attaches great importance to Economics Science and Management Science. Its courses at bachelor stage include core courses of Health Management and Business Management and its courses at master stage include management courses and those related to Health major. There are even more at doctor stage, almost involving courses related to each discipline field. Thus most of doctors majored in Health Management in America are jointly trained by Management College, Medical College and Business College.

\section{Teaching methods}

American universities all attach great attention to the teaching methods. No matter in which college the major of Health Management is set, they all focus on training the ability of solving problems for students. Initiative study and practical teaching have become the main teaching and learning way for the major of Health Management. Many universities require students to pursue full-time study in medical institutions on holiday. Some other universities require students to finish internship lasting for at least 11 months after learning theoretical courses for two years. After students finish corresponding learning stage and training task, they are required to prepare literature review and graduating topic related to the major. The graduating topics involve some problems existed in the practical American health industry and they must be solved after practice and practical investigation. Therefore, such teaching method can upgrade students' practical operation ability and their ability to solve practical problems, very beneficial to the training of professional health management talents. 


\section{Chinese Health Management Talent Training}

In contrast to America, the training of health management talents in China has been influenced by objective economic system and administrative management system from the very beginning. For long time, the training of health management talents focuses more on theory than practice, and more on medical disciplines than management disciplines.

\section{Educational system and training system}

The health management talents in China are mainly trained by each medical college. From the very beginning, they were trained by the way of cadre training. Then it developed to adult education special training and now there is hierarchy academic education. Now Chinese training system for health management talents is complete from junior education to doctor education. In consideration of training goals, training plans and course setting, domestic universities learn from each other mutually with no obvious difference. But they all regard medical disciplines to be the basis for learning other majors, which is very unfavorable for health management talent training. Meanwhile, due to the difference in education level and professional teaching among schools, they train students with different levels. Thus, it causes slow development of the team of health management talents (2). At the new century, many medical colleges were merged into comprehensive universities, but the major of Health Management in many schools are still led by medical colleges. Only a few schools have established Health Management College.

\section{Teaching contents and courses setting}

The courses for Health Management in China are mainly dominated by Health Management and Public Health, Health Management and Preclinical Medicine. It is a single teaching mode. The teaching contents fail to conform to the social demand that talents trained do not satisfy the society. Meanwhile, the teaching contents are too one-sided that most of them focus on basic medicine and public health lacking other disciplines. There are little natural science knowledge and cultural social science. Only medical disciplines are over stressed. At the master education stage, Social Medicine and Health Science are over stressed. Although American MHA is trying to be introduced, there appears confusion with NIBS and MPA in the practical operation process, failing to reflect the cross-discipline characteristics. Meanwhile, as to courses for health management talents, they are totally the same with those for Inspection and Quarantine, Clinic Treatment. Thus, it appears that teachers are not willing to teach, while students are not willing learn. Schools are required to train health management talents, while the teaching lacking management can not train qualified talents. But Chinese teaching can not effectively connect with the practical condition of the current medical health industry. The teaching contents are blind, not gearing to the needs of the job. The thinking mode for training is also rather confused.

\section{Teaching methods}

In consideration of the current teaching methods of Chinese universities, although the training plans for many majors pay attention to the training of practical operation ability, most of schools still focus more on theoretic knowledge than practical teaching. It is not an exception for the teaching of health management. Most of the time is used in theoretical teaching, and there is great shortage of practical operation. Such "duck-stuffing" teaching method forces classroom teaching occupying most of the time for students, while the time for experiment teaching and practical activity only occupies one eighth of the total credit hours. This can explain why our students are so weak in practical operation ability. Meanwhile, such teaching method only stressing theoretical teaching goes against the principles of cognition and thinking. Rigid pattern and low quality obstruct students' enthusiasm. Students trained by such teaching method can definitely not be competence for the management posts in the medical health industry. It not only wastes the national resource, but also wastes students' time. 


\section{Comparison of Health Management Talent Training Modes between Two Countries and the Reference for China}

Through the above analysis, it can see that there exists great difference between two countries in training health management talents. Chinese training mode focus more on theory, separating away from the requirement of students' quality and knowledge structure in the medical industry and neglecting the function of practice. While America pays great attention to the requirement of students' theory and practice, forming a very mature training system. Therefore, China needs to improve the following aspects to upgrade the effect of training health management talents.

\section{Focus on the cognition of health management disciplines and change the theory-style training mode.}

The management level in the medical industry is very important. It determines the operation of the health industry for the whole society to great extent. With such a large population in China, the medical health industry in many regions develops at slow speed and there is limitless space for future development. With the national reformation of medical industry, it requires more professional management talents. Regarding the above analysis, Chinese health management talent training focuses more on theory and academy than practical operation. So it is difficult to give play to its function in the medical industry. Therefore, we can refer to American health management education plan based on our own practical condition in training plan, courses setting, teaching contents and methods. Meanwhile, it shall strengthen students' study of natural disciplines and cultural disciplines as basic courses. During the teaching process, teachers shall choose practical cases in the medical health industry for teaching as possible as they can to enrich the teaching contents. Meanwhile, they shall focus on students' practical activities and internship to increase professional ability.

\section{Strengthen the disciplinary knowledge system and the hierarchy of talent training}

In China, the health management education trains from the junior education to doctor education. In addition, there are special post training and further education. Due to different positioning of training hierarchy, there is also great difference in courses setting. Regarding that medical institutions of different levels propose different requirements for management posts, it shall analyze and make research on the professional disciplinary system. It must reflect the hierarchy and direction in courses setting, teaching contents and teaching methods. It shall make clear that whether to train research-style talents or those who will be engaged in the health policy and medical insurance. It shall further complete the disciplinary system and accurately master the study direction to enhance post adaptive ability and the professional nature of health management.

\section{Strengthen the teaching staff construction for health management}

In consideration of the relative shortage of teachers for health management in China, it must strengthen the disciplinary staff construction and the training of teachers. According to the development demand of the current teaching staff team, it shall employ experts who are skilled in certain aspects with professional background home and abroad. Meanwhile, it shall establish training bases to strengthen the training of the current teaching staff. Make training plans and include them into the training plan of the Education Department. Implement practical and effective measures to build a qualified teaching team. Encourage the medium and senior talents engaged in the medical industry to join the teaching team for guiding students' practical activities and internship.

\section{References}

[1] Zhou Jian, Discussion of the Academic Connotation in the Field in Consideration of the Health Management Courses in American Universities [J]. Journal of China Hospital Management, 2000 (4).

[2] Wang Jinpeng, Problems in the Current Health Management Education and Countermeasures [J]. China Health Management, 2002 (9). 